\title{
Numerical evaluation of clay disturbance during blade penetration in the flat dilatometer test
}

\author{
G. P. KOURETZIS*, Y. ANSARI*, J. PINEDA*, R. KELLY*† and D. SHENG*
}

\begin{abstract}
This paper presents a study on the amplification of horizontal soil stresses during flat dilatometer test (DMT) blade penetration based on three-dimensional total and effective stress numerical analyses, while considering stress-flow coupling and large deformations. The focus here is on saturated clays, and the effect of soil stress history on the horizontal stress index is discussed in detail. The obtained results appear to be in good agreement with published and new field data, leading to the proposal of two new expressions for estimating the overconsolidation ratio and the earth pressure coefficient at rest directly from flat dilatometer tests in estuarine clays.
\end{abstract}

KEYWORDS: clays; in situ testing; numerical modelling

ICE Publishing: All rights reserved

\section{INTRODUCTION}

One of the key intermediate parameters obtained from the flat dilatometer test (DMT) is the horizontal stress index $\left(K_{\mathrm{D}}\right)$, defined as

$$
K_{\mathrm{D}}=\frac{P_{0}-u_{0}}{\sigma_{\mathrm{v} 0}^{\prime}}
$$

where $P_{0}$ is the calibrated 'lift-off' pressure required to initiate movement of the membrane against the soil, $u_{0}$ is the hydrostatic pore pressure at the depth of testing and $\sigma_{\mathrm{v} 0}^{\prime}$ is the in situ effective overburden stress. Building on the strong correlation of the soil stress history with $K_{\mathrm{D}}$ (Jamiolkowski et al., 1988; Lacasse \& Lunne, 1988), various researchers proposed expressions to calculate the overconsolidation ratio (OCR) from the horizontal stress index for non-cemented clays (Marchetti, 1980; Powell \& Uglow, 1988; Kamei \& Iwasaki, 1995). These expressions imply that $K_{\mathrm{D}}$ depends only on the stress history, and any effect of other soil parameters is overlooked. Additionally, as OCR has an effect on the earth pressure coefficient at rest $\left(K_{\mathrm{o}}\right)$, several researchers (e.g. Marchetti, 1980; Lacasse \& Lunne, 1988; Powell \& Uglow, 1988) proposed empirical expressions to estimate $K_{\mathrm{o}}$ from flat dilatometer tests.

In ideal conditions, if blade insertion did not introduce any disturbance to the surrounding soil before the lift-off pressure is measured, the horizontal stress index would be equal to $K_{\mathrm{o}}$, as equation (1) implies. However, penetration of the blade will result in some amplification of the in situ horizontal stresses and $K_{\mathrm{D}}$ will actually be higher than the earth pressure coefficient at rest, $K_{\mathrm{D}}>K_{\mathrm{o}}$. To the authors' knowledge, there is still a gap in the literature regarding the quantitative estimation of the effect of soil disturbance on the value of $K_{\mathrm{D}}$, which is based on the empirical cointerpretation of field and laboratory data. Marchetti et al. (2001) suggest that in 'genuinely normally consolidated

Manuscript received 19 February 2015; first decision 6 April 2015; accepted 20 April 2015.

Published online at www.geotechniqueletters.com on 15 July 2015.

*ARC Centre of Excellence for Geotechnical Science and Engineering, The University of Newcastle, Callaghan, NSW, Australia

†Coffy Geotechnics, Sydney, NSW, Australia
(NC) clays' (i.e. not exhibiting ageing, structure or cementation effects) the value of $K_{\mathrm{D}}$ is $K_{\mathrm{D}, \mathrm{NC}} \approx 2$, which is widely embraced today. In a more systematic approach, Finno (1993) employed the strain path method (Baligh, 1985; Huang, 1989) to calculate the strain field developing around the blade during penetration in saturated clays and quantify soil disturbance effects. Finno (1993) concluded that the horizontal stress index in normally consolidated clays is in the range $K_{\mathrm{D}, \mathrm{NC}}=1 \cdot 30-1 \cdot 97$, depending on the soil mechanical properties, which is generally lower than most field measurements reported in the literature.

In the following an attempt is made to delve into the relationship between $K_{\mathrm{D}}, K_{\mathrm{o}}$ and OCR for non-cemented saturated clays by numerically simulating DMT blade penetration into soil with a three-dimensional (3D) finite-element model (Fig. 1). The complete dilatometer test sequence, which includes inflation of the membrane, is not simulated: the goal here is to obtain the average horizontal stress acting on the membrane before its inflation, which is equal to $P_{0}$, as a function of the clay properties. The main novelty of this approach compared with the admittedly sparse literature on numerical simulation of the DMT is that the blade is 'pushed in place' instead of 'wished in place' (e.g. Luo \& Xu, 2006), thus providing the opportunity to directly compare $K_{\mathrm{D}}$ to $K_{\mathrm{o}}$, which is an input parameter. The results obtained from a parametric analysis for different soil stress histories are compared against the compilation of field data presented by Kamei \& Iwasaki (1995), data from UK clays presented by Powell \& Uglow (1988) and new data from the National Soft Soil Test Facility established in Ballina, Australia on soft estuarine clay deposits (Pineda et al., 2014; Kelly et al., 2015). Finally, new formulas are proposed to estimate OCR and $K_{\mathrm{o}}$ from $K_{\mathrm{D}}$ for non-cemented estuarine clays and future applications of the particular methodology are discussed.

\section{NUMERICAL MODEL}

Owing to the geometry of the flat dilatometer blade and the membrane, the full 3D problem must be simulated to properly account for the amplification of horizontal soil stresses in the vicinity of the membrane (Finno, 1993). One of the most challenging aspects of such an analysis is simulating the penetration of the blade into the soil without severe element distortion compromising the accuracy of the solution. 


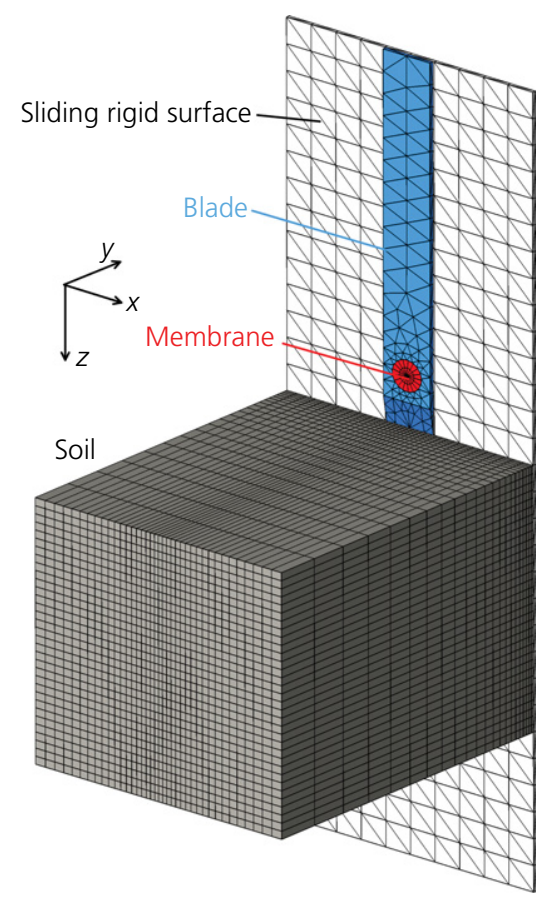

Fig. 1. 3D finite-element model of the soil-blade-membrane system developed in Abaqus

To tackle this problem, a smooth rigid surface is used, whose face is parallel to the vertical axis of symmetry of the blade (Fig. 1). This surface, which slides together with the blade during penetration, allows soil nodes to translate inwards to conform to blade penetration, but not outwards to violate the symmetry boundary conditions (Kouretzis et al., 2014).

The analysis is executed in two steps. First, geostatic stress equilibrium is achieved in a soil 'sample' of dimensions $500 \mathrm{~mm} \times 600 \mathrm{~mm} \times 500 \mathrm{~mm}$, which is considered to be under constant vertical effective stress $\sigma_{\mathrm{v} 0}^{\prime}=50 \mathrm{kPa}$. The corresponding horizontal stress is calculated while assuming that $K_{\mathrm{o}}$ is equal to (Ladd et al., 1977)

$$
K_{\mathrm{o}}=K_{\mathrm{o}, \mathrm{NC}} \mathrm{OCR}^{0.5}=\left(1-\sin \varphi^{\prime}{ }_{\mathrm{cs}}\right) \mathrm{OCR}^{0.5}
$$

where $\varphi^{\prime}$ cs is the critical state friction angle. Equilibrium is retained throughout the analysis by applying constant pressures on the non-fixed faces of the mesh. It should be noted here that the presented results do not depend on the actual value of the overburden stress $\sigma^{\prime}{ }_{\mathrm{v} 0}$, as the horizontal stress index is dimensionless. This hypothesis was confirmed during the early stages of the study by performing additional analyses while applying increased vertical stresses of $\sigma_{\mathrm{v} 0}^{\prime}=$ $100 \mathrm{kPa}$ and $\sigma_{\mathrm{v} 0}^{\prime}=200 \mathrm{kPa}$.

The dimensions of the mesh were optimised on the basis of a sensitivity analysis to eliminate boundary effects on the results. The width of the sample perpendicular to the blade $(600 \mathrm{~mm})$ must be two orders of magnitude larger than the half-thickness of the blade $(7.5 \mathrm{~mm})$ in order to avoid fictitious amplification of the horizontal stress. On the other hand, the minimum element size of the mesh representing the soil needs to be small enough to accommodate rapid stress variations near the blade. For that, brick elements of minimum dimensions $5 \mathrm{~mm} \times 10 \mathrm{~mm} \times 25 \mathrm{~mm}$ and a graded mesh to minimise computational cost are used. The steel blade is modelled as a smooth, linear elastic solid body of $95 \mathrm{~mm}$ width. The apex angle is $30^{\circ}$ and the tapered section is $50 \mathrm{~mm}$ long. The membrane's diameter is $60 \mathrm{~mm}$ and its thickness is $1.5 \mathrm{~mm}$, as per a standard DMT rig (Marchetti et al., 2001). The contact pressure acting on the 58 nodes of the membrane is obtained during the second stage of the analysis, after the blade is pushed into the soil for $200 \mathrm{~mm}$ at a rate of $10 \mathrm{~mm} / \mathrm{s}$, which is a typical depth increment of the DMT test. Penetration of the blade is achieved by applying a uniform vertical displacement on all nodes of the solid body comprising the blade and the membrane, whereas the same displacement vector is applied on the rigid sliding surface, which is connected to the blade. Note that only the outer (peripheral) nodes of the membrane are fixed on the body of the blade and therefore the membrane is free to deflect inwards as a result of increasing lateral pressure from the soil during penetration.

\section{BENCHMARK TOTAL STRESS AND EFFECTIVE STRESS ANALYSES WITH STRESS-FLOW COUPLING}

As blade penetration takes place under undrained conditions, the total stresses acting on the membrane will be mainly due to the development of excess pore pressures, at least in normally and lightly overconsolidated saturated clays (Mayne, 1987; Finno, 1993). Still, as we are interested in obtaining the contact pressure on the soil-membrane interface, a total stress analysis with a simple elasto-plastic model obeying a Tresca yield criterion would suffice for describing the non-cemented clay response. Such a total stress approach is much more computationally efficient than an effective stress analysis, and would essentially provide similar results. To support that, the two approaches are compared by also using the modified Cam-clay (MCC) model to perform a $3 \mathrm{D}$ coupled stress-flow analysis to simulate blade penetration in a normally consolidated saturated clay.

Both total and effective stress analyses are performed under an in situ overburden effective stress $\sigma_{\mathrm{v} 0}^{\prime}=50 \mathrm{kPa}$, while the horizontal stress is calculated while considering the horizontal stress index from equation (2) as $\sigma_{\mathrm{h} 0}^{\prime}=K_{\mathrm{o}} \sigma_{\mathrm{v} 0}^{\prime}=$ $21.6 \mathrm{kPa}$. The parameters of the MCC model correspond to soft estuarine Ballina clay (Pineda et al., 2014) and are presented in Table 1. This Holocene clay is mainly composed of smectite, kaolinite and mica/illite and has an organic content lower than 5\%. Its liquid limit varies from 55 to $130 \%$ whereas its plasticity index ranges from 50 to $75 \%$. The relatively high friction angle $\varphi_{\text {cs }}^{\prime} \approx 35^{\circ}$ results from the high natural salinity of the pore fluid (electrical conductivity $(\mathrm{EC})=36 \mathrm{mS} / \mathrm{cm})$. The presence of osmotic potential $(\mathrm{EC}>$ $0)$ results in an increase in the friction angle of saturated clays, as observed by Pineda et al. (2013) in Ballina clay samples.

The equivalent elasto-plastic model parameters can be derived directly from the MCC parameters. The undrained Young's modulus is equal to

$$
E_{\mathrm{u}}=\frac{3 E^{\prime}}{2\left(1+v^{\prime}\right)}=\frac{9\left(1-2 v^{\prime}\right) v_{0} p^{\prime}{ }_{0}}{2\left(1+v^{\prime}\right) \kappa}
$$

where $p_{0}^{\prime}=\left(\sigma^{\prime}{ }_{\mathrm{v} 0}+2 \sigma^{\prime}{ }_{\mathrm{h} 0}\right) / 3$ is the in situ mean stress.

Table 1. Modified Cam-clay parameters

\begin{tabular}{l|c}
\hline Slope of the virgin consolidation line, $\lambda$ & $0 \cdot 8$ \\
Slope of the recompression/swelling line, $\kappa$ & $0 \cdot 08$ \\
Slope of the critical state line, $M$ & $1 \cdot 4$ \\
$M=6 \sin \varphi^{\prime}$ cs $/\left(3-\sin \varphi^{\prime}{ }_{\mathrm{cs}}\right)$ & \\
Initial specific volume, $v_{0}=1+e_{0}$ & $4 \cdot 0$ \\
Poisson's ratio, $v$ & $0 \cdot 33$ \\
Dry unit weight, $\gamma_{\mathrm{dry}}=G_{\mathrm{s}} \gamma_{\mathrm{w}} /\left(1+e_{0}\right)$ & $6 \cdot 62 \mathrm{kN} / \mathrm{m}^{3}$ \\
Permeability, $k$ & $10^{-8} \mathrm{~m} / \mathrm{s}$ \\
\hline
\end{tabular}


The undrained shear strength $S_{\mathrm{u}}$ is calculated as (Potts \& Zdravkovic, 1999)

$$
\begin{aligned}
\frac{S_{\mathrm{u}}}{{\sigma^{\prime}}{ }_{\mathrm{v} 0}}= & g(\theta) \cos (\theta) \frac{\mathrm{OCR}}{6}\left(1+2 K_{\mathrm{o}, \mathrm{NC}}\right)\left[1+B^{2}\right] \\
& \times\left(\frac{2\left(1+2 K_{\mathrm{o}, \mathrm{OC}}\right)}{\left(1+2 K_{\mathrm{o}, \mathrm{NC}}\right) \mathrm{OCR}\left(1+B^{2}\right)}\right)^{\kappa / \lambda}
\end{aligned}
$$

where $\theta=-30^{\circ}$ is Lode's angle for triaxial compression conditions (Potts \& Zdravkovic, 1999); $g(\theta)$ is equal to

$$
g(\theta)=\frac{\sin \varphi_{\mathrm{cs}}^{\prime}}{\cos \theta+\left(\sin \theta \sin \varphi_{\mathrm{cs}}^{\prime}\right) / 3^{1 / 2}}
$$

and $B$ is equal to

$$
B=\frac{3^{1 / 2}\left(1-K_{\mathrm{o}, \mathrm{NC}}\right)}{g\left(-30^{\circ}\right)\left(1+K_{\mathrm{o}, \mathrm{NC}}\right)}
$$

The OCR here is defined in terms of vertical effective stress as OCR $=\sigma^{\prime}{ }_{\mathrm{vp}} / \sigma^{\prime}{ }_{\mathrm{v} 0}$, with $\sigma_{\mathrm{vp}}^{\prime}$ being the maximum vertical effective stress the soil has been subjected to in the past. Equations (3)-(6) suffice for calculation of the equivalent elasto-plastic model parameters. For example, a normally consolidated clay with the MCC parameters of Table 1 can be simulated as a Tresca material with $S_{\mathrm{u}}=$ $16.4 \mathrm{kPa}, E_{\mathrm{u}}=1793 \mathrm{kPa}$ and undrained Poisson's ratio $v_{\mathrm{u}}$ of about 0.5 (Table 2).

Results from the benchmark analyses are compared in Fig. 2, in terms of the mean horizontal stress developing on the membrane as it penetrates into the soil. For the total stress analyses, the results of two different soil meshes are presented: one discretised with quadratic twenty-node brick elements (C3D20) and one with linear eight-node elements

Table 2. Summary of parametric analyses input values

\begin{tabular}{l|c|c|c|c}
\hline OCR & $K_{\mathrm{o}}$ & $E_{\mathrm{u}}: \mathrm{kPa}$ & $S_{\mathrm{u}}: \mathrm{kPa}$ & $v_{\mathrm{u}}$ \\
\hline 1 & $0 \cdot 432$ & 1793 & $16 \cdot 4$ & $0 \cdot 49$ \\
2 & $0 \cdot 611$ & 2137 & $31 \cdot 1$ & $0 \cdot 49$ \\
4 & $0 \cdot 865$ & 2624 & $59 \cdot 3$ & $0 \cdot 49$ \\
8 & $1 \cdot 223$ & 3313 & $113 \cdot 4$ & $0 \cdot 49$ \\
16 & $1 \cdot 729$ & 4287 & $217 \cdot 1$ & $0 \cdot 49$ \\
32 & $2 \cdot 446$ & 5665 & $416 \cdot 6$ & $0 \cdot 49$ \\
64 & $3 \cdot 459$ & 7613 & $800 \cdot 7$ & $0 \cdot 49$ \\
\hline
\end{tabular}

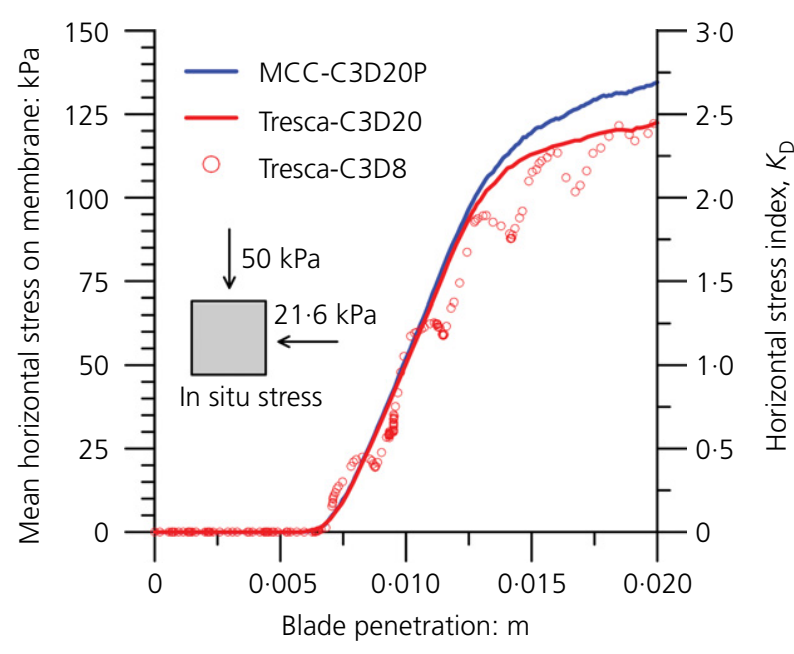

Fig. 2. Mean horizontal stress developing on the membrane during penetration of the blade from the benchmark analyses
(C3D8). The latter are more efficient in modelling the response of incompressible materials and are capable of simulating blade penetration in stiff clays with high OCR values, at the expense of the numerical noise depicted in Fig. 2. However, this does not affect the ultimate mean pressure developing on the membrane after its full penetration into the soil. Apart from the expected fair agreement between effective and total stress analysis results, note also that the $K_{\mathrm{D}}$ value for this normally consolidated clay is equal to $K_{\mathrm{D}, \mathrm{NC}}=2.69$ ( $\mathrm{MCC}$ analysis) or $K_{\mathrm{D}, \mathrm{NC}}=2.45$ (Tresca analysis). This is in agreement with the mean empirical value $K_{\mathrm{D}, \mathrm{NC}} \approx 2$ reported in the literature, the results of Chang (1991) for recent marine clay deposits and tests in estuarine Ballina clay documented by Pineda et al. (2014) and Kelly et al. (2015). It was also confirmed that the main portion of the total stress acting on the membrane is mainly due to excess pore pressure development in the vicinity of the blade, not effective soil stresses (Fig. 3), at least for the low permeability soil considered here - which ensures undrained conditions. As the permeability changes for constant penetration rate, the actual magnitude of the excess pore pressure developing in the soil around the blade will vary, as depicted in Fig. 3. But the total stress does not change and therefore the horizontal pressure acting on the membrane (and thus $K_{\mathrm{D}}$ ) does not depend on the
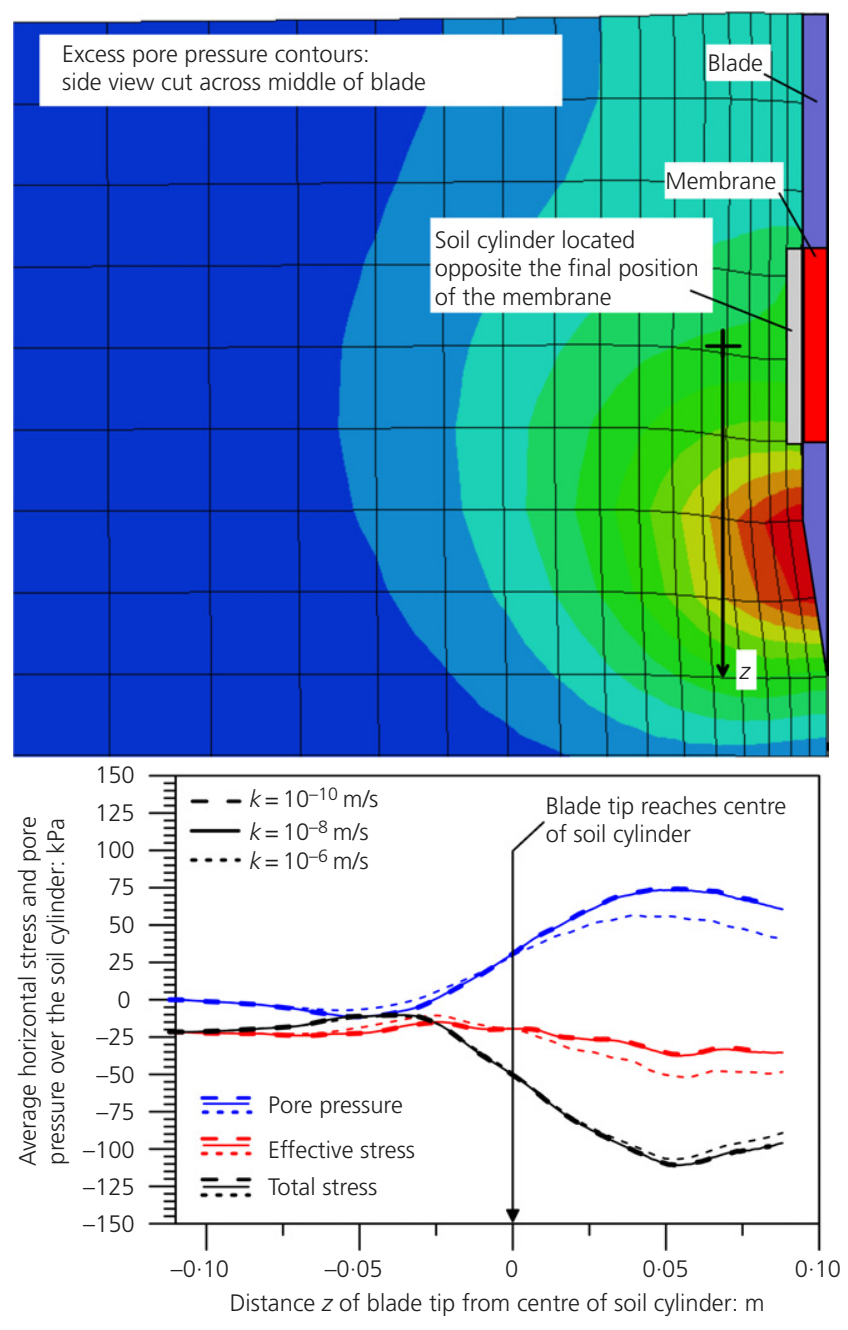

Fig. 3. Evolution of horizontal stress and pore pressure averaged over a cylinder of soil located opposite the final position of the membrane (vertical penetration $200 \mathrm{~mm}$ ). Results for three different soil permeability values are shown. Compressional stresses are negative 
permeability, at least for the range of soil permeabilities examined here.

\section{EFFECT OF SOIL STRESS HISTORY AND COMPARISON WITH FIELD MEASUREMENTS}

This section investigates parametrically the effect of OCR on the horizontal stress index $K_{\mathrm{D}}$ as the clay stiffness and the undrained shear strength vary according to equations (3)-(6) and $K_{\mathrm{o}}$ varies according to equation (2). For this purpose, additional analyses were performed considering OCR values ranging from 1 to 64 . The Ballina clay (Table 1) elastoplastic properties and $K_{\mathrm{o}}$ values corresponding to these OCR values are listed in Table 2. Results of these analyses are compared against published correlations and field measurements (Marchetti, 1980; Mayne, 1987; Lacasse \& Lunne, 1988; Powell \& Uglow, 1988; Chang, 1991; Kamei \& Iwasaki, 1995; Pineda et al., 2014; Kelly et al., 2015) in Figs 4 and 5. For OCR values less than $10, K_{\mathrm{D}}-\mathrm{OCR}$ combinations appear compatible with the expression proposed by Lacasse \& Lunne for high-plasticity clays $(\mathrm{OCR}=$ $0 \cdot 225\left(K_{\mathrm{D}}\right)^{1 \cdot 35}$ ) and Powell \& Uglow for young clays. For higher OCR values, the results appear to better match Marchetti's interpretation. To account for this, the following fitting expression is proposed to estimate OCR from $K_{\mathrm{D}}$ for young clays, which also matches well the laboratory and field data from Ballina clay

$$
\mathrm{OCR}=0.58 \mathrm{e}^{0.23 K_{\mathrm{D}}}
$$

Similar trends are observed on attempting to correlate the input $K_{\mathrm{o}}$ values (which vary with the stress history according to equation (2)) with the calculated $K_{\mathrm{D}}$ in Fig. 6 . The results again appear compatible with the expression of Lacasse \& Lunne for high-plasticity clays $\left(K_{\mathrm{o}}=0.34\left(K_{\mathrm{D}}\right)^{0.44}\right)$ in the common $K_{\mathrm{o}}$ value range, while they approach Marchetti's expression for highly overconsolidated clays. Numerical results can be curve-fitted with the following expression, whose range of application is limited to young clays

$$
K_{\mathrm{o}}=0.36 \mathrm{e}^{0 \cdot 11 K_{\mathrm{D}}}
$$

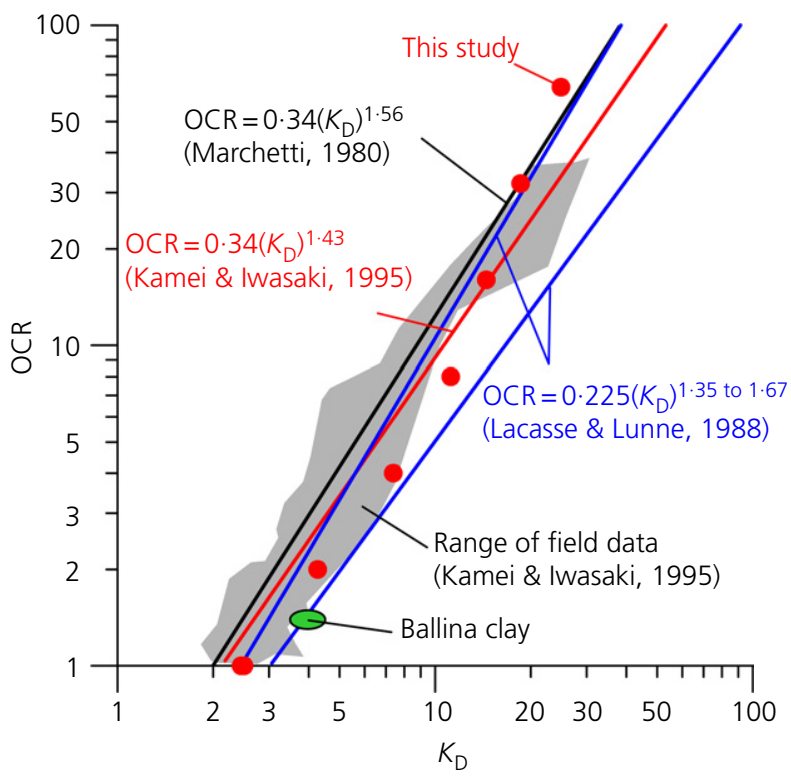

Fig. 4. Comparison of numerically obtained $K_{D}-\mathrm{OCR}$ values with empirical expressions and field data from Marchetti (1980), Mayne (1987), Lacasse \& Lunne (1988), Chang (1991), Kamei \& Iwasaki (1995), Pineda et al. (2014) and Kelly et al. (2015)

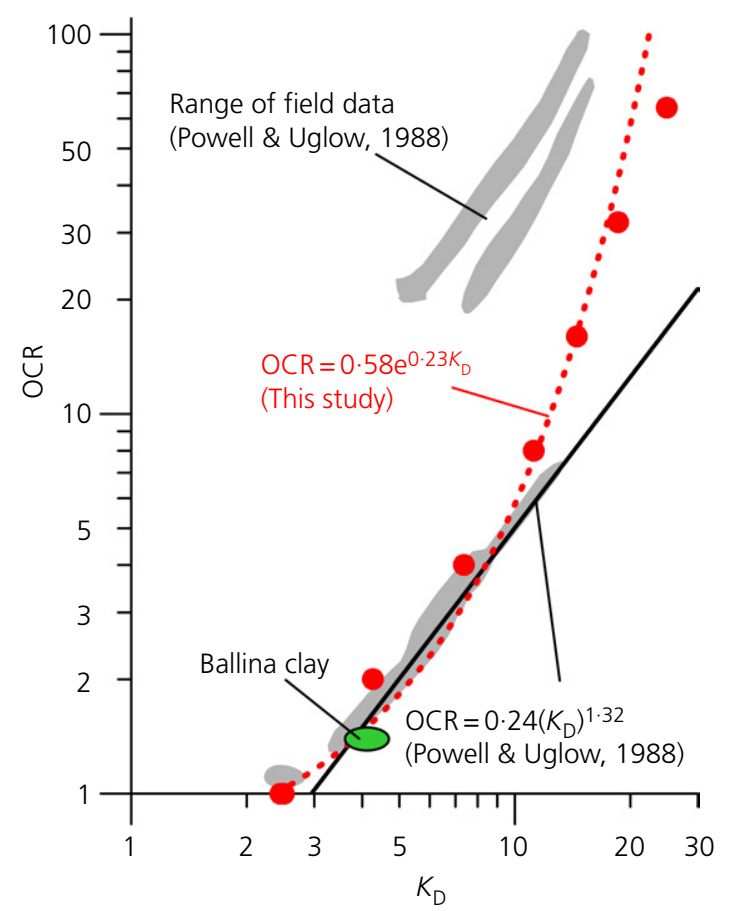

Fig. 5. Comparison of numerically obtained $K_{\mathrm{D}}-\mathrm{OCR}$ values with data from Powell \& Uglow (1988), Pineda et al. (2014) and Kelly et al. (2015)

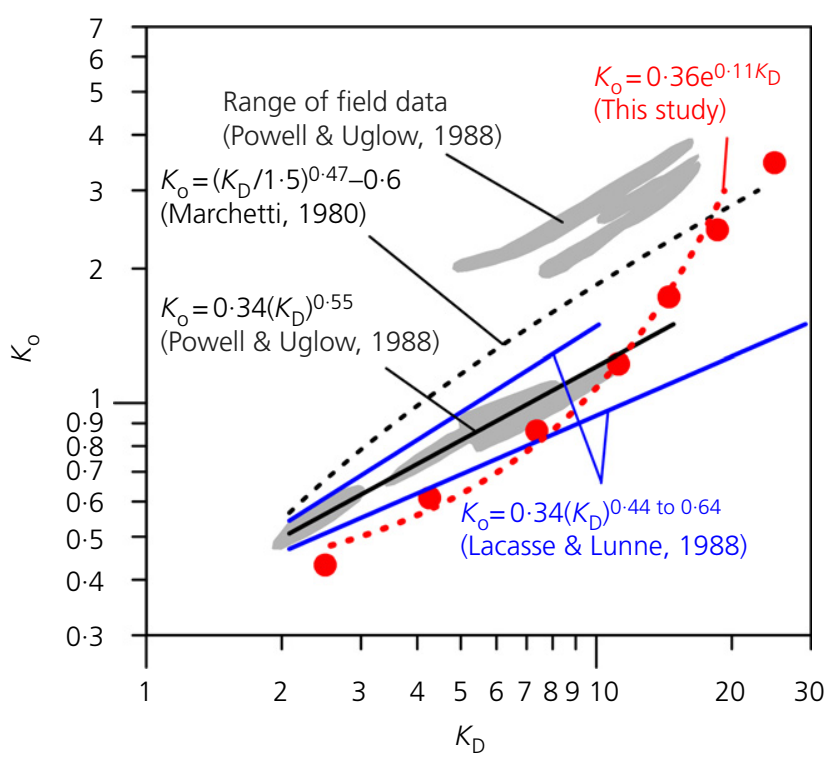

Fig. 6. Comparison of the proposed $K_{\mathrm{D}}-K_{\mathrm{o}}$ correlation with field data from Powell \& Uglow (1988) and the empirical expressions by Marchetti (1980), Lacasse \& Lunne (1988) and Powell \& Uglow (1988)

\section{DISCUSSION}

This numerical study focused on quantifying the amplification of horizontal soil stresses during DMT blade penetration and on an attempt to correlate it with the stress history of the clay. It has been shown that the horizontal stress index for a normally consolidated estuarine clay is about $K_{\mathrm{D}, \mathrm{NC}}=2 \cdot 5$, which is close to the empirical value of $K_{\mathrm{D}, \mathrm{NC}} \approx 2$ almost unequivocally adopted in practice. Curvefitting of the numerical results resulted in new expressions to estimate OCR and $K_{\mathrm{o}}$ from $K_{\mathrm{D}}$ for young soft clays. The results of additional analyses (not presented here) suggest 
that $K_{\mathrm{D}}$ is much less sensitive to other problem parameters such as the void ratio, the slope of the critical state line or even the formula used to pre-calculate $K_{\mathrm{o}}$ (equation (2)). This is in line with findings reported by Finno (1993) and must be seen in the light of significant scatter of field data.

The presented numerical methodology can be extended to provide additional insights into the interpretation of DMT measurements. Apart from soil disturbance effects, it can be used for simulation of the membrane inflation stage after pushing the blade in place, which cannot be achieved with alternative numerical techniques such as the strain path method (Finno, 1993).

\section{REFERENCES}

Baligh, M. M. (1985). Strain path method. ASCE J. Geotech. Div. 111, No. 9, 1108-1136.

Chang, M. (1991). Interpretation of overconsolidation ratio from in situ tests in recent clay deposits in Singapore and Malaysia. Can. Geotech. J. 28, No. 2, 210-255.

Finno, R. J. (1993). Analytical interpretation of dilatometer penetration though saturated cohesive soils. Géotechnique 43, No. 2, 241-254.

Huang, A.-B. (1989). Strain path analyses for arbitrary threedimensional penetrometers. Int. J. Anal. Num. Methods Geomech. 13, No. 5, 551-564.

Jamiolkowski, M., Ghionna, V., Lancellotta, R. \& Pasqualini, E. (1988). New correlations of penetration tests for design practice. Proc. Int. Symp. on Penetration Testing ISOPT-1, Orlando, FL, 1, pp. 263-296.

Kamei, T. \& Iwasaki, K. (1995). Evaluation of undrained shear strength of cohesive soils using a flat dilatometer. Soils and Found. 35, No. 2, 111-116.

Kelly, R., Bates, L. \& Pineda, J. (2015). Comparisons of DMT with in situ and laboratory tests in soft estuarine clay. Proc. 3rd Int. Conf. on the Flat Dilatometer, Rome.
Kouretzis, G. P., Sheng, D. \& Wang, D. (2014). Numerical simulation of cone penetration testing using a new critical state constitutive model for sand. Comput. Geotech. 56, $50-60$.

Lacasse, S. \& Lunne, T. (1988). Calibration of dilatometer correlations. Proc. Int. Symp. on Penetration Testing ISOPT-1, Orlando, FL, 1, pp. 539-548.

Ladd, C. C., Foott, R., Ishihara, K., Schlosser, F. \& Poulos, H. G. (1977). Stress-deformation and strength characteristics. Proc. 9th Int. Conf. on Soil Mechanics, Tokyo 2, pp. $421-494$.

Luo, S. \& Xu, C. (2006). Numerical modeling of the flat dilatometer test. In Site and geomaterial characterization. Reston, VA: ASCE, Geotechnical special publication 149.

Marchetti, S. (1980). Insitu tests by flat dilatometer. $A S C E$ J. Geotech. Engng Div. 106, No. 3, 299-321.

Marchetti, S., Monaco, P., Totani, G. \& Calabrese, M. (2001). The flat dilatometer test (DMT) in soil investigations. A report by the ISSMGE committee TC16. Proc. Int. Conf. on in situ Measurement of Soil Properties, Bali, pp. 1-41.

Mayne, P. W. (1987). Determining preconsolidation stress and penetration pore pressures from DMT contact pressures. Geotech. Test. J. 10, No. 3, 146-150.

Pineda, J., McConnell, A. \& Kelly, R. (2014). Performance of an innovative direct-push piston sampler in clay. Proc. 3rd Int. Symp. on Cone Penetration Testing CPT14, Las Vegas, NV, pp. 279-288.

Pineda, J. A., Kelly, R., Bates, L., Sheng, D. \& Sloan, S. (2013). Effects of pore fluid salinity on the shear strength of a soft clay. Proc. 5th ASCE Biot Conference on Poromechanics, pp. $1460-1469$.

Potts, D. M. \& Zdravkovic, L. (1999). Finite element analysis in geotechnical engineering: theory. London: Thomas Telford.

Powell, J. J. M. \& Uglow, I. M. (1988). The interpretation of Marchetti dilatometer tests in UK clays. Proc. ICE Penetration Testing in the UK, Birmingham, pp. 269-273.

\section{WHAT DO YOU THINK?}

To discuss this paper, please email up to 500 words to the editor at journals@ice.org.uk. Your contribution will be forwarded to the author(s) for a reply and, if considered appropriate by the editorial panel, will be published as a discussion. 